\title{
Can Asylum-Seekers with Posttraumatic Stress Disorder Be Successfully Treated? A Randomized Controlled Pilot Study
}

\author{
Frank Neuner ${ }^{1}$, Silke Kurreck ${ }^{2}$, Martina Ruf ${ }^{2}$, Michael Odenwald ${ }^{2}$, \\ Thomas Elbert ${ }^{2}$ and Maggie Schauer ${ }^{2}$ \\ ${ }^{\prime}$ Department of Psychology, Bielefeld University, Bielefeld, Germany; ${ }^{2}$ Department of \\ Psychology, University of Konstanz, Konstanz, Germany
}

\begin{abstract}
Rates of posttraumatic stress disorder (PTSD) are exceptionally high among asylumseekers. Reportedly, stressors caused by the asylum procedure and psychological consequences of torture contribute to the maintenance of symptoms and interfere with treatment. In a pilot randomized controlled trial, the authors examined the efficacy of trauma-focused treatment in 32 asylum-seekers with PTSD resulting from state-sponsored violence and other traumatic events. Narrative exposure therapy (NET) was compared with treatment as usual (TAU), with a focus on stabilization and psychoactive medication. Six months after treatment, a significant reduction of posttraumatic stress symptoms was found in the NET participants but not in the TAU group. Although treatment gains were moderate, these results indicate that NET is a promising approach for the treatment of PTSD in asylum-seekers living in unstable conditions. Key words: posttraumatic stress disorder; therapy; asylum-seekers; torture; refugees.
\end{abstract}

Received 17 February, 2009; Accepted 16 June, 2009

Correspondence address: Frank Neuner, Department of Psychology, Bielefeld University, Bielefeld, Germany.Tel: + 49521 106-4493. Fax: +49521 106-89012.E-mail: frank.neuner@uni-bielefeld.de

The vast majority of people who have fled from wars and political persecution remain in their country of origin or go to neighboring resource-poor countries. However, a minority of displaced people manage to flee to industrialized countries to seek asylum. As a consequence, most industrialized countries have set up legal procedures to decide on refugee status (i.e. a temporary or permanent permit to stay). In most European states, the legal asylum procedure can take up to several years. During this period, the asylum-seekers remain a distinct group within their host countries, with limitations in terms of freedom of movement, labor permit, and access to health care. Asylum-seekers usually only receive short-term temporary leave to remain and expect a sudden deportation to their home country following a formal decision.
Epidemiological studies have shown that asylum-seekers and refugee populations are characterized by exceptionally high rates of traumatic events, including war and torture experiences. As a consequence, a large percentage of asylum-seekers and refugees suffer from trauma-related mental health disorders. In particular, posttraumatic stress disorder (PTSD) is a very common syndrome, with prevalence rates in different populations ranging from 11 to $65 \%$ (Gerritsen et al., 2004). In accordance with these studies, a German survey found that $40 \%$ of newly-arrived asylum-seekers from different countries fulfilled the diagnostic criteria of PTSD (Gabel, Ruf, Schauer, Odenwald, \& Neuner, 2006).

These findings indicate a great need for psychological and psychiatric treatment in refugee populations. In recent years, knowledge about effective treatment of 
PTSD has been rapidly increasing. Current guidelines recommend trauma-focused psychotherapy as first-line treatment for patients with PTSD (Foa, Keane, \& Friedmann, 2000; National Institute for Clinical Excellence [NICE], 2005). Trauma-focused psychotherapy encompasses a variety of approaches that directly target the traumatic event in psychotherapy. In general, measures include encouraging the patient to talk about the traumatic event in detail and to relive the experience in a safe environment.

However, transformation of these recommendations to traumatized refugees is not straightforward, because cultural and language barriers as well as a complex history of traumatic experiences, including torture, pose challenges to psychotherapy. However, a small randomized controlled trial with 16 refugees in Sweden (Paunovic \& Öst, 2001) has found that trauma-focused therapy, either exposure treatment alone or a combination of cognitive and exposure intervention, leads to a significant reduction of PTSD symptoms. Unfortunately, this study was limited by strict inclusion criteria, because therapy was offered only to refugees with residency status and fluent speakers of the host country language. In another randomized controlled trial, Otto et al. (2003) tested a culturally adapted cognitive behavioral trauma-focused treatment in combination with antidepressant medication versus medication alone in female Cambodian refugees resettled in the United States. These findings and further studies (Hinton et al., 2004, 2005; Schulz, Resick, Huber, \& Griffin, 2006) substantiated the conclusion that trauma-focused treatment procedures, in particular cognitive behavioral methods, are effective for the treatment of refugees (Nicholl \& Thompson, 2004).

Despite these promising research findings, evaluation studies from highly reputed treatment centers in Europe have found very limited or no effectiveness of PTSD treatment for asylum-seekers and refugees (Birck, 2001, 2004; Carlsson, Mortensen, \& Kastrup, 2005). One reason for these disappointing results could be that these treatment centers have a tradition of applying a variety of treatment approaches, including psychodynamic and client-centered methods, but usually do not apply evidence-based trauma-focused approaches (Basoglu, 2006). However, many practitioners and representatives of treatment centers for refugees and torture victims insist that current evidence is not applicable to all groups of refugees. In particular, refugees with a history of torture presented with a very complex clinical picture that prevented the use of short-term trauma-focused approaches. Furthermore, traumatized asylum-seekers showed an exceptionally persistent pathology. Birck (2001, 2004) suggested that the unstable living conditions in the host country contributed to the resistance to treatment attempts. So far, no randomized trial on PTSD has included predominantly asylumseekers or torture victims.

The aim of this study was to examine whether trauma-focused treatment is feasible and effective for severely traumatized asylumseekers living in uncertain conditions. For this purpose, we recruited asylum-seekers and refugees with PTSD with a maximum leave to remain of 3 months. Another inclusion criterion was a history of state-sponsored violence (e.g. detainment and torture experiences). We applied narrative exposure therapy (NET; Schauer, Neuner, \& Elbert, 2005) as the treatment approach. NET is a trauma-focused short-term psychotherapy that was developed for the treatment of PTSD resulting from war and torture. Following the tradition of testimony therapy developed by Lira and Weinstein to treat victims of the Pinochet regime in Chile (Cienfuegos \& Monelli, 1983), NET focuses on the whole biography of the survivor, including all traumatizing events, rather than a specific event for therapy. The theoretical model of NET is based on a neurocognitive memory theory that predicts that the completion of the autobiographical memory of the traumatic events, including a connection of these representations to the fear memory, is one of the main agents of change within trauma therapy (Neuner et al., 2008). Unlike other trauma-focused approaches, the treatment explores the whole biography of the survivors without the need to specify a worst traumatic event before treatment. It is, therefore, well suited for victims of multiple and repeated traumatic experiences.

So far, NET has shown good effects in randomized trials with traumatized victims of war and persecution from different cultures and age ranges, including elderly survivors of political violence in Romania (Bichescu, 
Neuner, Schauer, \& Elbert, 2007) as well as war refugees living in refugee camps in Uganda (Neuner, Schauer, Klaschik, Karunakara, \& Elbert, 2004; Neuner et al., 2008), genocide victims in Rwanda (Schaal, Elbert, \& Neuner, 2009), and children suffering from the consequences of the war and the tsunami in Sri Lanka (Catani et al., 2009).

Within a pragmatic pilot trial, we compared the efficacy of NET with treatment as usual (TAU) as currently offered in the German health care system. To increase external validity, we offered treatment with interpreters for patients who were not fluent in German and we did not exclude patients with suicidal ideation, substance abuse, depression, or any other common comorbid disorder. The main outcome measure was posttraumatic stress symptoms assessed 6 months after treatment; the secondary measures were symptoms of common comorbid disorders, including depression and pain. Symptoms were assessed in structured clinical interviews before treatment and 6 months after NET treatment or a corresponding time period for the TAU group.

\section{Method}

\section{Participants}

The study was carried out at the Psychological Research and Outpatient Clinic for Refugees at the University of Konstanz. Participants were referred for diagnostic examination or treatment by general practitioners, aid organizations, lawyers, or judges. During the time of this study, $79 \%$ of the patients who were examined at the outpatient clinic reported physical torture experiences and $85 \%$ fulfilled the criteria for PTSD according to the Diagnostic and Statistical Manual of Mental Disorders (fourth edition [DSM-IV]; American Psychiatric Association, 1994). Each patient who was eligible for the study and lived close enough to the clinic for weekly appointments was offered participation in the trial. Inclusion criteria were asylum-seeker status with a temporary leave to remain, a history of victimization by organized violence, and the fulfillment of DSM-IV criteria for PTSD. In Germany, temporary leave to remain is issued for a maximum duration of 3 months and can be extended thereafter in case the requirements are still fulfilled.
Exclusion criteria were mental retardation, schizophrenia, and severe brain lesions requiring immediate treatment. However, none of the participants were excluded from the trial because of any of these reasons. Following our previous trial, we expected a between-treatment effect size (Cohen's $d$ ) of about 0.80 (Neuner et al., 2004). At a power level of $\mathrm{p} \beta=80$, we planned to have complete data from 26 patients for analysis (Chan, 2003). Assuming an attrition rate of $20 \%$, we anticipated a final sample size of 32 .

Participants gave written informed consent. The study protocol was approved by the University of Konstanz Ethical Committee. Participants were randomized into the two groups using a block permutation procedure with blocks of four patients. Table 1 shows the sociodemographic characteristics of the participants based on study groups. There was no significant difference in the characteristics between the two groups, as confirmed by Pearson chi-square tests, Fisher's exact tests, and $t$ tests.

Five participants in each group were still in the first stage of asylum process before a definite decision, and the others were refused asylum but received temporary leave to remain because of their impaired mental health condition or the current security situation in the home country. At posttest, two participants in the TAU group and three in the NET group were still in the asylum procedure, 13 (TAU) and 10 (NET) had exceptional leave to remain, and one in each group had received a permanent residence permit. The most common traumatic event types reported by the patients were witnessing a violent assault on a familiar person $(90.6 \%)$, torture $(87.5 \%)$, being in a war zone $(71.9 \%)$, and experiencing a violent assault by a stranger $(62.1 \%)$.

\section{Instruments}

Six clinical psychologists with extensive training in the examination of refugees with PTSD and the use of all instruments carried out the diagnostic assessments with the help of interpreters. As part of their training, each interviewer carried out diagnostic sessions under direct observation of one of the two senior clinicians. In these sessions, both clinicians completed the Posttraumatic Stress Diagnostic Scale (PDS; Foa, 1995) independently. 
Table 1. Baseline sociodemographic characteristics of participants divided by group

\begin{tabular}{|c|c|c|}
\hline Variable & $\mathrm{TAU}(n=16)$ & NET $(n=16)$ \\
\hline Age (years; $M, S D$ ) & $31.6(7.7)$ & $31.1(7.80)$ \\
\hline \multicolumn{3}{|l|}{ Sex } \\
\hline Male $(n, \%)$ & $11(68.8)$ & $11(68.80)$ \\
\hline Female $(n, \%)$ & $5(31.2)$ & $5(31.20)$ \\
\hline Education (years; $M, S D$ ) & $6.7(4.6)$ & $8.0(5.80)$ \\
\hline \multicolumn{3}{|l|}{ Origin $(n, \%)$} \\
\hline Turkey & $15(93.8)$ & $10(62.50)$ \\
\hline Balkans & $1(6.2)$ & $3(18.75)$ \\
\hline Africa & - & $3(18.75)$ \\
\hline Torture experiences $(n, \%)$ & $15(93.8)$ & $13(81.30)$ \\
\hline Months living in exile $(M, S D)$ & $47.6(39.5)$ & $63.5(45.50)$ \\
\hline Antidepressant medication $(n, \%)$ & $7(43.8)$ & $10(62.50)$ \\
\hline Drug abuse $(n, \%)$ & $4(25.0)$ & $2(12.50)$ \\
\hline \multicolumn{3}{|l|}{ Suicidal tendency $(n, \%)$} \\
\hline Plans or attempts & $4(25.0)$ & $9(56.30)$ \\
\hline Ideation or no tendency & $12(75.0)$ & $7(43.80)$ \\
\hline
\end{tabular}

Note. No difference reached statistical significance. TAU = treatment as usual; NET = narrative exposure therapy.

Only interviewers whose diagnoses and scores differed not more than 3 points from the expert clinician's rating on two consecutive occasions (1/3 SD of the PDS) were admitted to the study. Interviews with female survivors of organized violence were conducted with the help of female interpreters. All interpreters were trained for interviews and psychotherapy with torture survivors and signed a declaration of confidentiality at the beginning of a diagnostic interview or psychotherapy.

The assessment included a detailed structured interview about demographic data, physical health, education, and marital as well as asylum status. DSM-IV diagnosis and symptom frequency of PTSD were assessed using the PDS (Foa, 1995). We used a combination of the DSM-IV algorithm and the cutoff score of 17 as the criteria for the diagnosis of PTSD with the PDS, which has shown good agreement with the Clinician Administered PTSD Scale (CAPS) in a previous validation study (Griffin, Uhlmansiek, Resick, \& Mechanic, 2004). For the assessment of traumatic experiences during war, imprisonment, and torture, the VivoChecklist of Organized Violence (VCOV) ${ }^{1}$ was administered. It consists of 44 torture- and war-related event types commonly reported by refugees. Pain symptoms were assessed using part $C$ of the Composite International Diagnostic Interview (CIDI-C; World Health
Organization, 1997). For data analysis, the sum of pain symptoms was used as pain score. The Hopkins Symptom Checklist-25 (HSCL25; Derogatis, Lipman, Rickels, Uhlenhuth, \& Covi, 1974) Depression scale was used to assess comorbid symptoms of depression. All instruments were assessed in the form of structured interviews.

\section{Procedure}

Each respondent received one initial interview (sociodemographics, VCOV, PDS, HSCL-25, CIDI-C). In addition to participation in this trial, patients were offered a neuropsychological examination using magnetoencephalographic mapping of abnormal brain activity and measuring brain responses to emotional stimuli; results of this study will be described elsewhere.

Treatment took place at the psychological Research and Outpatient Clinic for Refugees. All but two treatments were carried out in outpatient settings. Because of a strong suicidal ideation, two patients in the NET group were admitted to the Psychiatric Ward of the University of Konstanz's Department of Psychology immediately after diagnosis. For these patients, NET therapy was offered in the ward as the only systematic treatment. Immediately after NET treatment, both patients could be released. In the TAU 
group, no patient had to be admitted to inpatient treatment.

For the NET patients, the posttests were scheduled 6 months after the end of treatment. For the participants in the TAU group, the timespans between pre- and posttest were individually matched with the NET group. We aimed at keeping interviewers blind to each participant's condition. However, occasionally, the participants revealed their condition to the interviewer despite instructions not to do so (e.g. by asking for treatment within the institution).

\section{Treatment}

NET treatment was carried out according to the manual (Schauer et al., 2005) by therapists from the University of Konstanz with the help of trained interpreters. Therapists were doctoral-level psychologists and graduate students with extensive training in NET. Frank Neuner and Maggie Schauer supervised the treatment. In supervision meetings, treatment progress, including the records of life histories, was evaluated. In addition, randomly selected treatment sessions (at least one per treatment) were directly observed by Maggie Schauer or Frank Neuner. Furthermore, all testimonies gained in NET treatment (biographical narrations usually exceeding 8000 words) were checked for indicators of vividness and consistency to ensure proper application of NET. No major deviations from treatment protocol were detected.

The first session included psychoeducation about the nature of PTSD symptoms and the NET rationale. NET consisted of a median of nine treatment sessions $(M=8.79, S D=3.77$; range $=5-17$ ) with an average duration of 120 minutes. Sessions were scheduled on a weekly or biweekly basis. Treatment was terminated at the therapist's discretion. As soon as the patient could, according to clinical judgment, talk about his or her traumatic experiences in detail without avoidance, memory gaps, or being emotionally overwhelmed, NET could be ended. In the last session, the participant received a written testimony of his or her biography.

Patients who were randomized to the TAU condition were encouraged to continue their current treatment or were referred to institutions of public mental health care when they were not in therapy or were dissatisfied with treatment. We aimed at a close monitoring of the treatments. However, there was almost no agreement between the reports of patients and therapists about number of sessions or medications used. In addition, some therapists refused to cooperate. Consequently, we could use only very basic information about the treatments applied in the TAU group. Except for one patient, all patients in the TAU condition received treatment, including psychotherapy with a focus on stabilizing methods $(n=6)$ and psychoactive medication $(n=12)$. None of the patients in the TAU group received trauma-focused treatment.

\section{Analysis}

Baseline characteristics of the groups were compared using chi-square tests for categorical variables and analyses of variance for continuous variables to examine the effects of randomization. Aiming at an intention-to treat analysis, all participants who were randomized were included in the outcome analysis. Because the aim of the study was to gain preliminary evidence about the efficacy of NET, we considered a last-observation-carried-forward procedure to be too conservative. Instead, we chose to apply mixed-effects models that allow the inclusion of all available data without the arbitrary replacement or imputation of missing values. Recent simulation studies have indicated that mixed-effect models are more accurate than even statistical multiple imputation strategies in dealing with missing data (Fong, Rai, \& Lam, 2006). For the outcome variables PDS, HSCL-25 Depression, and CIDI-Pain, we calculated mixed-effects models, including subject as random effect and treatment, time, and Treatment $\times$ Time as fixed effects, whereby subject was nested in treatment. Clinical significance was estimated by calculating within- and between-treatment effect sizes (Cohen's $d$; difference between means of an outcome measure at two time points or two groups divided by the pooled standard deviation for these means) for PTSD, HSCL25 Depression, and CIDI-Pain.

In addition to the group-level analyses, improvement and worsening of posttraumatic symptoms were explored at an individual level. The two patients with missing data at posttest were counted as unchanged for this purpose. Following the suggestion of Jacobson 
and Truax (1991), improvement of the PDS score was considered as statistically reliable at $\alpha=.05$ if the difference between the individual pre- and posttest score exceeded the cutoff value of $c_{i}=z_{5 \%} \times S E_{l t}=1.64 \times 6.15=10.1$, where $S E_{t t}$ is the standard error of the difference between two administrations of the PDS. This value was calculated on the basis of the standard error of measurement $S E_{m}$ of the PDS, which was determined from the standard deviation and the retest reliability $\left(r_{t t}\right)$ of the PDS in the normative sample (Foa, Zoellner, Feeny, Hembree, \& Alvarez-Conrad, 2002) using the following formula:

$$
S E_{t t}=\sqrt{2 \times S E_{m}^{2}}=\sqrt{2 \times\left(S D \sqrt{1-r_{t t}}\right)^{2}}
$$

To explore potential risks of treatment, worsening of symptoms on an individual level was analyzed in addition to the improvements. A reliable worsening was constituted if the increment of the PDS score between pre- and posttest exceeded the cutoff value described previously.

\section{Results}

\section{Participation}

Two patients from the NET group but no patient from the TAU group dropped out of the study. One NET treatment could not be carried out according to the manual because a severe hyperventilation syndrome interfered with narrative exposure. This patient was excluded from the study. Another patient dropped out of the NET group before the first exposure session because he refused to continue. Both patients were not available for follow-up examination. In the TAU group, the number of patients taking antidepressant medication rose from seven to 10 , whereas in the NET group the number declined from 10 to five. (See Figure 1 for a flow chart of study participants.)

\section{Scores}

Results on the outcome variables are presented in Table 2. For the PDS sum score, we found a significant main effect of time, $F(1$, $29.2)=17.9$, no main effect of treatment, $F(1,29.6)=2.47, p=.13$, but a significant Time $\times$ Treatment interaction, $F(1$, $29.2)=7.27, p=.01$. No significant main effect was found for the HSCL-25 Depression scale, of neither treatment, $F(1,29.6)=1.14$, $p=.30$, nor Time, $F(1,29.0)=3.72, p=.06$. Likewise, we found no significant Time $\times$ Treatment interaction, $F(1,29.0)=1.51$, $p=.29$. For the CIDI-C pain score, a significant Time $\times$ Treatment interaction was found, $F(1,28.9)=4.97, p=.034$, but no significant main effect of time, $F(1$, $28.9)=0.57, p=.46$, or treatment, $F(1$, $30.0)=0.90, p=.35$. However, after a Bonferroni-Holm alpha adjustment on the interaction tests of the secondary measures of pain and depression, the effect of pain does not remain significant. At posttest, all trial participants, except for one patient in the NET group, still fulfilled PTSD criteria. The difference in diagnostic status between groups was not significant. Between-treatment effect sizes (Cohen's $d$ ) were 1.04 for the PDS, 0.54 for the HSCL-25 Depression scale, and 0.65 for the CIDI-Pain score.

\section{Change score at individual level}

An improvement of posttraumatic stress symptoms as reflected by a decrease in PDS score was observed in 12 of 16 patients in the NET group, two patients presented with an increase in PDS score, and data were unavailable for another two patients. In the TAU group, half of the participants $(n=8)$ showed a decrease on the PDS. Counting the patients with incomplete data as unchanged, individual change exceeded the level of statistically reliable improvement $(\alpha=5 \%)$ for 10 of $16(63 \%)$ participants in NET group and three of $16(19 \%)$ in the TAU group, $\chi^{2}(1$, $N=32)=6.35, p=.01$. An increase in PDS score between pre- and posttest was observed in two patients $(13 \%)$ in the NET group and eight $(50 \%)$ in the TAU group. This increase did not reach the threshold for reliable worsening for any of the patients at $\alpha=.05$.

\section{Discussion}

In a randomized controlled comparison of a trauma-focused treatment (NET) with TAU, we found a significantly better trajectory for NET patients than TAU patients in the 6 months after treatment in terms of PTSD and pain symptoms but no difference related to depression symptoms. Contrary to the caveats commonly expressed in German guidelines and textbooks (summarized in Neuner, 2008), 


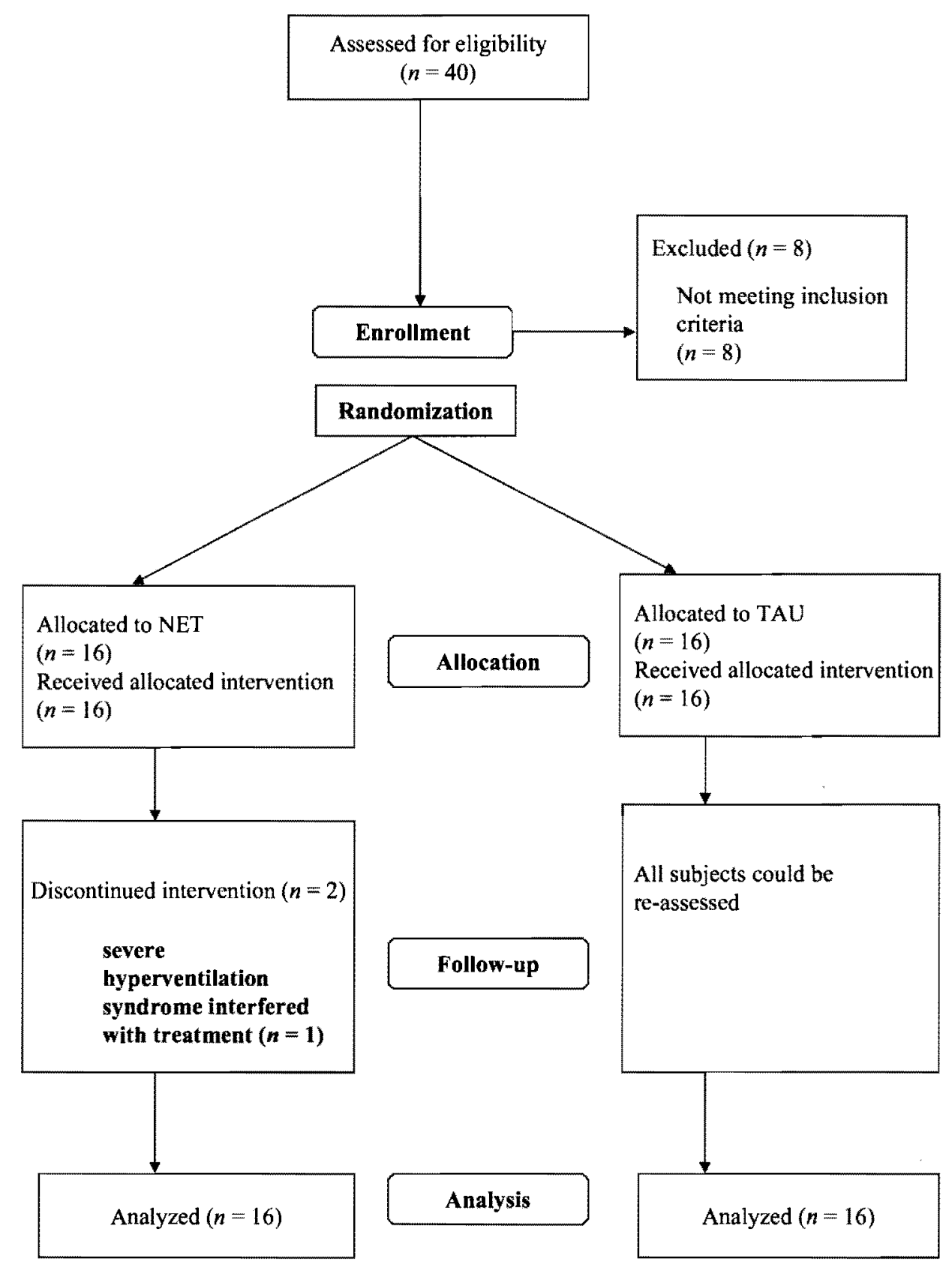

Figure 1. Flow chart of study participants.

we found that NET was generally well tolerated even by severely traumatized asylum-seekers living in unsafe conditions. Although an increase in the PDS score between pre- and posttest was observed for two patients in the NET group, this is hardly an indication of symptom exacerbation caused by exposure treatment, because the percentage of patients showing an increase in scores was significantly lower in the NET group than in the TAU group. Furthermore, none of the increases were statistically reliable. Only two participants $(13 \%)$ dropped out of NET treatment, and treatment could be continued for both patients outside the trial. The dropout rate was lower than the figures reported in most other treatment studies using exposure and nonexposure treatments for PTSD, with averages of about $20 \%$ (Grinage, 2003; Hembree et al., 2003). The motivation to receive a written biography upon completion could be an important motivator. Many participants in the NET group reported that they submitted this 
Table 2. Means and standard deviations within-treatment effect sizes (Cohen's d) of the outcome variables by group

\begin{tabular}{lccc}
\hline Treatment group & Pre & Post & ES pre to post \\
\hline Sample size & 16 & & \\
NET & 16 & 14 & \\
TAU & 16 & 1.6 \\
Posttraumatic Stress Diagnostic Scale $(M, S D)$ & & 0.4 \\
NET & $38.9(6.4)$ & $26.0(9.2)$ & \\
TAU & $36.9(8.0)$ & $34.1(6.1)$ & 0.8 \\
Hopkins Symptom Checklist-25 & Depression scale $(M, S D)$ & & 0.2 \\
NET & $3.0(0.4)$ & $2.6(0.6)$ & \\
TAU & $3.0(0.5)$ & $2.9(0.5)$ & 0.3 \\
Composite International Diagnostic Interview-C Pain score $(M, S D)$ & -0.7 \\
NET & $5.6(2.5)$ & $4.9(1.9)$ & $5.4(1.7)$ \\
TAU & $3.9(2.7)$ & &
\end{tabular}

Note. $N E T=$ narrative exposure therapy; $T A U=$ treatment as usual $E S=$ effect size.

document to the court to prove human rights violations even when it was of no help in the asylum process. In addition, some participants passed the testimony to human rights organizations to indicate that torture is still practiced in some countries even though it is presented differently to the public.

The difference between the participants between groups was significant with regard to PTSD symptoms. In addition, the withingroup effect sizes were high, the betweengroup effect sizes medium to high, and the majority of NET patients improved to a statistically reliable extent. However, the endstate status of participants was not satisfying because all but one patient in the NET group and all patients in the TAU group still fulfilled PTSD criteria. Likewise, we did not find a significant treatment effect on depression symptoms. Studies using other variants of exposure therapy with patients from industrialized countries (Foa et al., 2005; Resick, Nishith, Weaver, Astin, \& Feuer, 2002) as well as NET with former political prisoners in Romania (Bichescu et al., 2007) have reached a better end-state status with regard to PTSD diagnosis and better recovery rates for depression symptoms. One explanation for the worse outcome could be that participants in this trial started with a higher symptom level than the nonrefugee populations of other studies. The participants in the NET group entered the study with a mean PDS score of $38.9(S D=6.4)$, whereas scores in other studies using compatible instruments reported lower entry scores, ranging from 26.1 (Nishith, Nixon, \& Resick, 2005 ) to 34.0 (Foa et al., 2005). Alternatively, the unsafe living conditions, including the permanent threat of deportation as well as other postmigration stressors, might interfere with any treatment of an anxiety disorder. Except for two participants who had been granted asylum, all were still in the application process at posttest, which implies several restrictions in daily life such as living in a reception center, no work permit, little allowance, and frequently separation from family. For example, lack of employment has been found to be associated with anxiety and depression (Lavik, Hauff, Skrondal, \& Solberg, 1996). Steel et al. (2004) found that asylum-seekers often perceive their future to be entirely in the hands of an impersonal bureaucracy, which intensifies feelings of helplessness and loss of control over one's life. Likewise, Basoglu et al. (2005) reported that fear of threat to safety and loss of control over life appeared to be the most important mediating factors in PTSD and depression. These exile stressors could explain why pain symptoms, which can depend on stress, have increased in the TAU group. Future studies should use larger sample sizes, including a higher variance in objective postmigration stressors (i.e. by including refugees with permits to stay for varying lengths of time), and subjective measures of distress to test the 
predicted impact of exile stressors on treatment effect.

Although this study showed that NET was superior to TAU in this setting, we cannot prove that the NET procedure itself was responsible for the difference between groups. In particular, we cannot rule out a mere dosage effect of unspecific treatment factors. Unfortunately, we could not monitor the TAU treatments closely enough to get a good account of the procedures. Although we tried to assess the number of treatment sessions and the medications received, the reports from patients and therapists did not correspond and so we decided not to use this information. Another limitation of this study is that a considerable number of patients in the NET group took antidepressant medication throughout the trial. This might increase the dosage effect of treatment, because these patients received a combination therapy. Furthermore, we cannot fully rule out an assessor bias because blindness could not be maintained in all cases.

Because this study indicates that psychotherapy can facilitate recovery of torture victims and asylum-seekers and that NET may be particularly useful, the findings encourage the implementation of well-controlled dismantling studies to identify essential treatment components for this population. Furthermore, this trial supports the general recommendation of trauma-focused treatment approaches for PTSD issued by the International Society of Traumatic Stress Studies (Foa, 2000 ) and NICE (2005). Even though asylumseekers and torture victims may need a longer treatment and the involvement of different disciplines, a trauma-focused module could be an important part of treatment.

\section{Acknowledgments}

The study was funded by the Deutsche Forschungsgemeinschaft and the European Refugee Fund. We thank Katy Robjant for editing an earlier version of this article.

\section{Note}

1. Available from the authors upon request.

\section{References}

American Psychiatric Association. (1994). Diagnostic and statistical manual of mental disorders (4th ed.). Washington, DC: Author.

Basoglu, M., Livanou, M., Crnobaric, C., Franciskovic, T., Suljic, E., Duric, D., et al, (2005). Psychiatric and cognitive effects of war in former Yugoslavia: Association of lack of redress for trauma and posttraumatic stress reactions. Journal of the American Medical Association, 294, 580-590.

Basoglu, M. (2006). Rehabilitation of traumatised refugees and survivors of torture. British Medical Journal, 333, 1230-1231.

Bichescu, D., Neuner, F., Schauer, M., \& Elbert, T. (2007). Narrative exposure therapy of political imprisonment-related chronic trauma spectrum disorders: A randomized controlled trial. Behaviour Research and Therapy, 54, 2212-2220.

Birck, A. (2001). Torture victims after psychotherapy: A two-year follow up. Torture, 11, 55-58.

Birck, A. (2004). Symptomatik bei kriegs-und folteruberlebenden Fluchtlingen, mit und ohne Psychotherapie [Symptoms in refugees who survived torture or war, with and without psychotherapy]. Zeitschrift für klinische Psychologie und Psychotherapie, 33, 101-109.

Carlsson, J. M., Mortensen, E. L., \& Kastrup, M. A. (2005). Follow-up study of mental health and health-related quality of life in tortured refugees in multidisciplinary treatment. Journal of Nervous and Mental Disease, 193, 651-657.

Catani, C., Kohiladevy, M., Ruf, M., Schauer, E., Elbert, T., \& Neuner, F. (2009). Treating children traumatized by war and tsunami: A comparison between exposure therapy and meditation relaxation in North-East Sri Lanka. $B M C$ Psychiatry, 9, 22.

Chan, Y. H. (2003). Randomised controlled trials (RCTs)-Sample size: The magic number? Singapore Medical Journal, 44(4), 172-174.

Cienfuegos, A. J., \& Monelli, C. (1983). The testimony of political repression as a therapeutic instrument. American Journal of Orthopsychiatry, 53, 43-51.

Derogatis, L. R., Lipman, R. S., Rickels, K., Uhlenhuth, E. H., \& Covi, L. (1974). The Hopkins Symptom Checklist (HSCL): A selfreport symptom inventory. Behavioral Science, $19,1-15$.

Foa, E. B. (1995). Post-traumatic diagnostic scale. Minneapolis, MN: National Computer Systems.

Foa, E. B. (2000). Psychosocial treatment of posttraumatic stress disorder. Journal of Clinical Psychiatry, 6l(Suppl. 5), 43-48.

Foa, E, B., Hembree, E. A., Cahill, S. P., Rauch, S.A., Riggs, D.S., Feeny, N.C., et al. (2005). Randomized trial of prolonged exposure for posttraumatic stress disorder with and without cognitive restructuring: Outcome at academic and community clinics. Journal of Consulting and Clinical Psychology, 73, 953-964. 
Foa, E. B., Keane, T. M., \& Friedmann, M. J. (2000). Effective treatments for PTSD. New York: Guilford Press.

Foa, E. B., Zoellner, L. A., Feeny, N. C., Hembree, E. A., \& Alvarez-Conrad, J. (2002). Does imaginal exposure exacerbate PTSD symptoms? Journal of Consulting and Clinical Psychology, $70(4), 1022-1028$

Fong, D. Y. T., Rai, S. N., \& Lam, K. S. L. (2006, September). Use of multiple imputation on linear mixed model and generalized equations for longitudinal data analysis: $A$ simulation study. Paper presented at the 13th International Conference of Forum for Interdisciplinary Mathematics, Tomar, Portugal.

Gerritsen, A. A., Bramsen, I., Deville, W., van Willigen, L. H., Hovens, J. E., \& van der Ploeg, H. M. (2004). Health and health care utilisation among asylum seekers and refugees in the Netherlands: Design of a study. BMC Public Health, 4, 7

Griffin, M. G., Uhlmansiek, M. H., Resick, P. A., \& Mechanic, M.B. (2004). Comparison of the Posttraumatic Stress Disorder Scale versus the Clinician-Administered Posttraumatic Stress Disorder Scale in domestic violence survivors. Journal of Traumatic Stress, 17(6), 497-503.

Grinage, B. D. (2003). Diagnosis and management of post-traumatic stress disorder. American Family Physician, 68, 2401-2408.

Gabel, U., Ruf, M., Schauer, M., Odenwald, M., \& Neuner, F. (2006). Pravalenz der Posttraumatischen Belastungsstorung (PTSD) und Moglichkeiten der Ermittlung in der Asylverfahrenspraxis [Prevalence of posttraumatic stress disorder among asylum-seekers in Germany and its detection in the application process for asylum]. Zeitschrift für klinische Psychologie und Psychotherapie, 35, 12-20.

Hembree, E. A., Foa, E. B., Dorfan, N. M., Street, G. P., Kowalski, J., \& Tu, X. (2003). Do patients drop out prematurely from exposure therapy for PTSD? Journal of Traumatic Stress, $16,555-562$.

Hinton, D. E., Chhean, D., Pich, V., Safren, S. A., Hofmann, S. G., \& Pollack, M. H. (2005). A randomized controlled trial of cognitivebehavior therapy for Cambodian refugees with treatment-resistant PTSD and panic attacks: A cross-over design. Journal of Traumatic Stress, 18, 617-629.

Hinton, D. E., Pham, T., Tran, M., Safren, S. A., Otto, M. W., \& Pollack, M. H. (2004). CBT for Vietnamese refugees with treatment-resistant PTSD and panic attacks: A pilot study. Journal of Traumatic Stress, 17, 429-433.

Jacobson, N. S., \& Truax, P. (1991). Clinical significance: A statistical approach to defining meaningful change in psychotherapy research. Journal of Consulting and Clinical Psychology, $59(1), 12-19$

Lavik, N. J., Hauff, E., Skrondal, A., \& Solberg, O. (1996). Mental disorder among refugees and the impact of persecution and exile: Some findings from an out-patient population. British Journal of Psychiatry, 169, 726-732.

Neuner, F. (2008). Stabilisierung vor Konfrontation in der Traumatherapie-Grundregel oder Mythos? [Stabilization before confrontation in trauma treatment-Basic rule or myth?]. Verhaltenstherapie, 18, 109-118.

Neuner, F., Catani, C., Ruf, M., Schauer, E., Schauer, M., \& Elbert, T. (2008). Narrative exposure therapy for the treatment of traumatized children and adolescents (KidNET): From neurocognitive theory to field intervention. Child and Adolescent Psychiatric Clinics of North America, 17, 641-664.

Neuner, F., Schauer, M., Klaschik, C., Karunakara, U., \& Elbert, T. (2004). A comparison of narrative exposure therapy, supportive counseling, and psychoeducation for treating posttraumatic stress disorder in an African refugee settlement. Journal of Consulting and Clinical Psychology, 72, 579-587.

National Institute for Clinical Excellence. (2005). The management of posttraumatic stress disorder in primary and secondary care. London: Author.

Nicholl, C., \& Thompson, A. (2004). The psychological treatment of posttraumatic stress disorder (PTSD) in adult refugees: A review of the current state of psychological therapies. Journal of Mental Health, 13, 351-362.

Nishith, P., Nixon, R. D., \& Resick, P. A. (2005). Resolution of trauma-related guilt following treatment of PTSD in female rape victims: A result of cognitive processing therapy targeting comorbid depression? Journal of Affective Disorders, 86, 259-265.

Otto, M. W., Hinton, D., Korbly, N. B., Chea, A., Ba, P., Gershuny, B. S., et al. (2003). Treatment of pharmacotherapy-refractory posttraumatic stress disorder among Cambodian refugees: A pilot study of combination treatment with cognitive-behavior therapy vs. sertraline alone. Behaviour Research and Therapy, 4l, $1271-1276$.

Paunovic, N., \& Öst, L. G. (2001). Cognitivebehavior therapy vs. exposure therapy in the treatment of PTSD in refugees. Behaviour Research and Therapy, 39, 1183-1197.

Resick, P. A., Nishith, P., Weaver, T. L., Astin, M. C., \& Feuer, C, A. (2002). A comparison of cognitive-processing therapy with prolonged exposure and a waiting condition for the treatment of chronic posttraumatic stress disorder in female rape victims. Journal of Consulting and Clinical Psychology, 70, $867-879$

Schaal, S., Elbert, T., \& Neuner, F. (in press). Narrative exposure therapy versus interpersonal psychotherapy: A randomized controlled trial with Rwandan genocide orphans. Psychotherapy and Psychosomatics.

Schauer, M., Neuner, F., \& Elbert, T. (2005). Narrative exposure therapy: A short-term intervention for traumatic stress disorders after war, terror, and torture. Gottingen, Germany: Hogrefe \& Huber. 
Schulz, P. M., Resick, P. A., Huber, L. C., \& Griffin, M. G. (2006). The effectiveness of cognitive processing therapy for PTSD with refugees in a community setting. Cognitive and Behavioral Practice, 13, 322-331.

Steel, Z, Momartin, S., Bateman, C., Hafshejani, A., Silove, D. M., Everson, N., et al. (2004).
Psychiatric status of asylum seeker families held for a protracted period in a remote detention centre in Australia. Australian and New Zealand Journal of Public Health, 28, 527-536.

World Health Organization. (1997). Composite international diagnostic interview (CIDI). Geneva: Author. 